\title{
Prevalence and clinical features of pityriasis versicolor in children
}

\author{
A Rijal, S Agrawal, S Bhattarai \\ Department of Dermatology, B. P. Koirala Institute of Health Sciences, Dharan, Nepal
}

\begin{abstract}
Background: Pityriasis versicolor (P.versicolor) is a mild chronic infection of the skin caused by Malassezia yeasts. The disease is more prevalent in teenagers and adults and children are rarely affected. Objective: To study the prevalence and clinical presentation of P.versicolor in children. Methods: All children below 14years of age presenting with hypo pigmented macules were screened for P.versicolor. A $10 \% \mathrm{KOH}$ examination of skin scrapping was done in all the screened patients. A positive $\mathrm{KOH}$ mount showing spores and hyphae were included in the study. The clinical and epidemiological data was noted. Results: The total number of children with hypo pigmented macules was 102 and 58 were positive for PV. In 31.2\% patients the lesions were on the face and these patients were below 1 years of age. Most cases presented in the summer months. Oil massage was seen in all patients. Conclusion: Hypo pigmented macules in infants should be screened for PV as this is seen to be quite common. Occlusion due to oil massage may cause PV.
\end{abstract}

Keywords: pityriasis versicolor, children, hypo pigmented macules, oil massage

\section{Introduction}

Pityriasis versicolor (P.versicolor) is one of the common disorders of pigmentation seen in the tropics and sub-tropical regions especially during the summer months. It is a superficial fungal infection characterized by skin pigmentary changes due to colonization of the stratum corneum by a dimorphic lipophilic fungus known as malassezia furfur. ${ }^{1}$ It is an infection seen usually in early adulthood and small children are not or rarely affected though few studies $^{2-5}$ have shown children to be affected by P.versicolor. Children with an underlying infection, diabetes mellitus, malnutrition, HIV, on long term cortico-steroids or on any immunosuppressant and hyperhidrosis are more likely to have P.versicolor. ${ }^{6}$ The development of P.versicolor maybe related to an altered immune-response to the organism. The lesions are generally restricted to anatomical sites that are covered by clothing

Address for correspondence

Dr. Arpana Rijal

Additional Professor

Department of Dermatology and Venereology

B.P. Koirala Institute of Health Sciences, Dharan

Email:arpanarijal@yahoo.co.uk suggesting a role of increased heat and moisture in the pathogenesis of the disease. The lesions are usually seen on the trunk and upper extremities in adults whereas in children it can also be the face, trunk or extremities. A family history of P.versicolor is often present especially when the infection is seen in children. ${ }^{6}$

This study was done to know the prevalence and clinical pattern of P.versicolor in children, and also to see if the infection was due to an exogenous or endogenous cause.

\section{Methods}

This study was done over a one year period in the department of Dermatology at a tertiary care centre. All children between 0-14 years, presenting with hypo pigmented macules were screened for P.versicolor. A detailed history was taken to rule out diabetes, malnutrition, HIV infection, hyperhydrosis or if the patient was on corticosteroid or any other immunosuppressant drug. The clinical pattern of the lesions was recorded. A 10\% $\mathrm{KOH}$ mount was done from scrapings of the lesions. P.versicolor was 
diagnosed in patients whose skin scrapings showed spores and hyphae.

\section{Results}

The total number of patients attending the dermatology out patient in the one year study period was 15,000 .The total number of patients screened was 2640 and the number of patients in the age group 0-14 years with hypopigmented macules was 102 . The $10 \% \mathrm{KOH}$ mount positive in the patients with hypo pigmented macules was 58 (56.4\%) (Fig1).

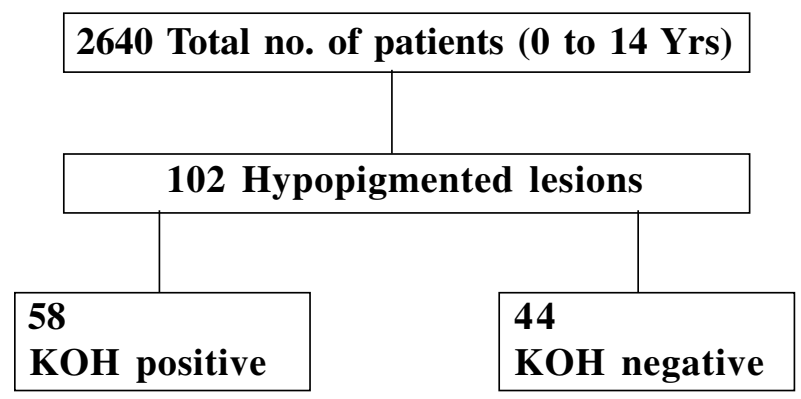

Fig 1: Total number of patients screened and positive with $P V$

The number of boys was 34 and girls 24 . The age range of the patients was from 2.5 - 168 months, mean 90.05months (SD18.5). The number of patients below 1 year of age was 11.Thirty-four percent (20) patients had the lesions for less than a month. Range for the duration of the disease was 1-6 months. The appearance was gradual in $79.3 \%$ (46) patients with a slow progression in $93 \%$ (54) patients. Fifty $(86.2 \%)$ patients presented in the summer months and a recurrence during this period was seen in 7 (12.1\%) of patients. A family history of P. versicolor was seen in only $4(6.9 \%)$ patients and itching was present in only $8.6 \%$ (5) patients. Diabetes mellitus, HIV, underlying infections or use of long term corticosteroids was not seen in any patient. All patients presented with hypopigmented macules, multiple in member, well defined $2-4 \mathrm{~mm}$ in size, discreet fine scaling was seen in only $75 \%$ (43 patients). The lesions were present on the face in $19 \%$ patients below 1 year of age and on 47 patients between 1-14 years of age. The scalp was involved in 2 patients below 1 years of age (Table 1). The other sites involvement were chest, back and arms. Mustard oil was used for body and hair massage in all patients (Table 2).
Table 1: Age and site of lesion

\begin{tabular}{|c|c|c|c|c|c|c|}
\hline \multirow{2}{*}{ Age } & \multirow{2}{*}{$\mathbf{N}(\boldsymbol{\%})$} & \multicolumn{5}{|c|}{ Site of Lesion } \\
\cline { 3 - 7 } & & Face & Neck & Back & Chest & Scalp \\
\hline <1 Years & $11(19 \%)$ & 11 & 8 & 5 & 2 & 2 \\
\hline 1-5 Years & $11(19)$ & 10 & 8 & 5 & 1 & - \\
\hline 6-10Years & $6(10.3)$ & 5 & 4 & 5 & 2 & - \\
\hline 11-14Years & $30(51.7)$ & 24 & 9 & 11 & 10 & - \\
\hline
\end{tabular}

Table 2: Risk factors for $\mathbf{P}$. versicolor

\begin{tabular}{|l|l|}
\hline Risk Factor & N (\%) \\
\hline Mustard oil massage & $58(100 \%)$ \\
\hline Hot and humid climate & $58(100 \%)$ \\
\hline Family history & $4(6.9 \%)$ \\
\hline
\end{tabular}

\section{Discussion}

Pityriasis versicolor, a fungal infection of the skin is seen in adults and teenagers. However, it may be seen in children too. The prevalence of the disease in the age group $0-14$ years was $56.4 \%$ of all hypopigmented macules screened. Though P.versicolor can present as hyperpigmented macules but we included only hypo-pigmented lesions in our study.

There was an increase in the incidence of P.versicolor during the summer and monsoon season. Studies from India ${ }^{2}$ show an increase in the disease in the monsoon. Bouassida also found an increase in the incidence during summer months. ${ }^{4}$

P.versicolor was seen in all age groups of children between 0-14 years with a higher number in patients between 10-14 years. The number of children below 1 year age was 11(19\%) which shows that young children can be affected too. The age of the youngest patient was 2-5 months. Isa-Isa reported a large number of patients below one year of age. ${ }^{3}$ In the hot and humid climates P.versicolor can be seen even in very young age-groups.

The most commonly affected site was the face followed by neck, thorax and upper extremities. Various studies have also shown the face to be mostly affected in children in contrast to that seen in adults having P.versicolor on the face secondary to the trunk, extremities. Two infants had lesions on the scalp along with lesions on the face. Naseri has reported P.versicolor on the scalp but the patient was 
a young boy presenting with similar lesions. ${ }^{10}$ The lesions in children were smaller, discrete, hypopigmented macules in contrast to the adults who have larger lesions even when lesions are present on the face.

None of the patients had an association with systemic disease or long term use of immunosuppressive drugs as seen more in temperature climates. The use of mustard oil for massage was seen in all patients and this could predispose to developing P.versicolor. Schwartz has suggested that topical application of olive oil could be one of the susceptibility factors for developing P.versicolor. ${ }^{11}$

\section{Conclusion}

Pityriasis versicolor in children below 14 years of age in tropical climates is common especially during the rainy season. Preferential facial localization in children is characteristic of childhood P.versicolor. $\mathrm{P}$ versicolor should be kept as a differential diagnosis in hypopigmented macules especially when on the face.

\section{References}

1. Gupta AK, Blubon R, Summerbell R. Pityriasis versicolor, JEADV 2002: 16, 19-33.

2. Jena DK, Sengupta S, Dwari BC, Ram HK. Pityriasis versicolor in the pediatric age group. Indian J Dermatol Venereol Leprol 2005 Jul-Aug; 71(4): 259-61.
3. Isa- Isa R, Cruz AC, Arenas R, Duarte Y, Linares $\mathrm{CM}$, Begaest $\mathrm{H}$. Pityriasis versicolor in infants under one year of age. A report of 92 cases Rev Iberoam Micol.2001 Sep; 18(3): 109-12

4. Bouassida S, Boudaya S, Ghorbel R, Meziou TJ, Marrckehi S, Turki H, Zahaf A. Pityriasis versicolor in children: a retropspecive study of 164 cases. Ann Dermatol Venerol 1998 Sep; 125(9): 581-4

5. Acosta QME, CarzolaPDJ: Clinical epidemiological aspects of pityriasis versicolor in a fishing community of the semi-arid region in Falcon State,Venezuela:Rev Iberoam Micol 2004 Dec:21:191-4

6. Sunenshine PJ, Schwartz RA, Janniger. Tinea versicolor Int J Dermatol 1998: 37: 648-655.

7. Terrangoni L, Lasagni A, Oriani A, Gelmetti C. Pityriasis versicolor in the pediatric age. Pediatric Dermatol 1991; 8: 9-12.

8. Miskeen AK, Kalkar SS, Shroff HJ. Pityriasis versicolor in children Indian J. Dermatol Venereol Leprol 1984; 50: 144-6

9. Terrangini L, Lasagni A, Orioni A. Pityriasis versicolor of the face. Mycoses 1991; 34: 345-7

10. Naseri M,Namazi MR:Isolated scalp involvement with pityriasis versicolor alba(pityriasis versicolor albus capitis)in a patient from a dry, temperate region :Dermatol Online J.2003 Aug;9:17

11. Schwartz RA. Superficial fungal infections. Lancet 2004; 364: 1173-84. 